\title{
Trend step changes of seasonal and annual precipitation over Kermanshah during a 60-year period using non-parametric methods
}

\author{
Amir Hossein Hashemian, ${ }^{1,3}$ Mansour Rezaei, ${ }_{1}^{2,3 *}$ Hajar Kashefi, ${ }^{3}$ Meghdad Pirsaheb ${ }^{1,4}$ and \\ Hassan Kharajpour ${ }^{5}$ \\ ${ }^{1}$ Research Center for Environmental Determinants of Health (RCEDH), Kermanshah University of Medical \\ Sciences, Kermanshah, Iran \\ ${ }^{2}$ Social Development and Health Promotion Research Centre, Kermanshah University of Medical Sciences, \\ Kermanshah, Iran \\ ${ }^{3}$ Department of Biostatistics, Faculty of Health, Kermanshah University of Medical Sciences, Kermanshah, Iran \\ ${ }^{4}$ Department of Environmental Health, Faculty of Health, Kermanshah University of Medical Sciences, \\ Kermanshah, Iran \\ ${ }^{5} \mathrm{PhD}$ student of Meteorology, Department of Geography, University of Kharazmi, Tehran, Iran
}

\begin{abstract}
One of the approaches usedtoinvestigate trend step changes in precipitation isstatistical techniques.The main objective ofthis paper is toidentify and analyze thetrend ofchanges in annual and seasonalprecipitation overthe studied area.The current study employs monthly precipitation data from 1951 to 2010 derived from a weather station in Kermanshah. Using non-parametric Mann-Kendall test and graphic based methods depicting total annual and seasonal (cold and warm seasons) precipitation, the research analyzes trend changes of Kermanshah over different time series. Primarily, data changes in studied seasons and years are analyzed. Then, type and time of these changes are identified. Averages of monthly precipitation overKermanshah during warm and cold seasons are determined as $47.9 \pm 33.64$ $\mathrm{Mm}$ and $169.68 \pm 54.56 \mathrm{Mm}$, respectively. There is no significant trend in annual precipitation over Kermanshah. Analysis of averages precipitation of warm and cold seasons indicates no significant trend; however, warm season seems to follow a decreasing trend in general. Yet, there are leaps in the average levels of both annual and seasonal precipitation. The obtained results show that general trend of change in average precipitation during warm seasons is downward with leaps of average during the studied period. But, in general, there is no significant trend of change in the averages of annual and seasonal precipitation during the studied time.
\end{abstract}

KEY WORDS: CHANGES OF PRECIPITATION, TREND ANALYSIS, ANNUAL, SEASONAL, KERMANSHAH, NON-PARAMETRIC MANN-KENDALL TEST

ARTICLE INFORMATION:

*Corresponding Author: rezaei39@yahoo.com Received 22 $2^{\text {nd }}$ Oct, 2017

Accepted after revision $27^{\text {th }}$ Dec, 2017

BBRC Print ISSN: 0974-6455

Online ISSN: 2321-4007 CODEN: USA BBRCBA

4homson Reuters ISI ESC and Crossref Indexed Journal

NAAS Journal Score 2017: 4.31 Cosmos IF: 4.006

๑ A Society of Science and Nature Publication, 2017. All rights reserved.

Online Contents Available at: http//www.bbrc.in/

DOI: $10.21786 / \mathrm{bbrc} / 10.4 / 8$ 


\section{INTRODUCTION}

Precipitation is the most important input data in hydrological cycle which needs to be considered mostly in runoff, drought, groundwater, flood and sediment studies. Now a day, global warming, caused by increasing greenhouse gases, and its effect on climate change is a scientific fact accepted by many researchers. Almost all processes in the biosphere are affected by climate change and the effect of this phenomenon on the environment and water resources is a matter of great concern. In order to be prepared against adverse effects of climate change and to reduce its resulting damages, it is necessary to study common trends of change in weather variables in each area so as to adopt proper policies and plans for development and management ofwater resources Katirai et al., (2007) Aziz and Burn (2006) and Chen et al., (2007)

To detect trends of weather variables in different time intervals various test may be used which can be divided into two groups: parametric and non-parametric tests. Parametric tests have more trend analysis potentials than non-parametric tests and require random (independent) data with normal distribution. On the other side, nonparametric tests are consistent with random data and are not sensitive to normal distribution. Mann-Kendall and Spearman are examples of these tests used in trend analysis of weather variables.

In general, trend analysis of climate change, changes in precipitation trend in particular, is among issues that have been considered by researchers of climate and hydrology science, in recent years. Regardless of climate status of a region (wet or dry), precipitation trend analysis of a region may aid executives and managers associated with water issue to make better decisions about implementation of future development projects. Considering that large parts of Iran is located in belt of arid and semi-arid regions of earth, on one hand, and important role of precipitation in supplying water resources of the country, on the other hand, has put more emphasis on gaining greater awareness of trends of precipitation over Iran. Broad investigations have been carried out to identify the process of precipitation over the whole world and Iran. With respect to the significant impact of precipitation on climate system numerous studies have been conducted, including the studies of Matyasovszky et al. 1993, Angel and Huff (1997) Keily et al (1998) Gellens (2000) Piccarreta et al. (2004) Xu et al. (2003) Turgay and Ercan (2005).

All of these studies, trend analysis of precipitation intervals is carried out using non-parametric tests. Trend analysis of precipitation in different time intervals using parametric and non-parametric methods has attracted the attention of many domestic researches, as well. Kamali (11) investigated precipitation trend of different stations during statistical period from 1986-1996 and found that precipitation trend was both increscent and decrescent depending on the region. He indicated that increscent trend has been more frequent Iran than decrescent trend.

Javeri investigated temporal changes in temperature and precipitation over Iran using statistical tests with fixed and variable model and proved that the variation is significant and these changes appear in the form of random displacements, changes in trend, seasonal fluctuations, and periodical changes. Accordingly, in term of temporal changes in temperature and precipitation, Iran is divided to five different zones. In this study, to measure seasonal and annual trend of precipitation data, two non-parametric tests, Mann-Kendall test and Sen's Estimator, are used and the results are compared. Proving the significance of precipitation trend in a given time interval cannot be decisive evidence on climate changes in a region on its own, however, it strengthens such a hypothesis. It is caused bymultiplicity offactors controlling the climate system (KamaliGh 1996., Javeri 2003 Serrano et al., (1999)

Kermanshah Province, situated in western Iran, spreads over an area of 25,000 km2 (9,560 square miles, roughly the size of Vermont), or 1.5 percent of the total area of the country (Fig.1). It lies between latitudinal $45.5^{\circ}$ and $48^{\circ} \mathrm{E}$, longitudinal $33.7^{\circ}$ and $35.3^{\circ} \mathrm{N}$. The province is bound on the south by Ilām Province, on the southeast by Lorestān Province, on the east by Hamad ān Province, on the north by Kordestān Province, and on the west by Iraq, with about $250 \mathrm{~km}$ of international borderline. The capital city of this province is Kermanshah (Ahmadi et al 2010 ).

The province is bound on the south by Ilām Province, on the southeast by Lorestān Province, on the east by Hamadān Province, on the north by Kordestān Province, and on the west by Iraq, with about $250 \mathrm{~km}$ of international borderline. Considering the geographical location of Kermanshah, studies of climate change during the past decades and identifying that it follows a trend or not, with respect to recent droughts and growing population, may affect making proper policies to deal with drought and proper consumption. Such a study has not been done in this way in the metropolis of Kermanshah, so far.

\section{MATERIAL AND METHODS}

To examine the trend of change in precipitation of Kermanshah and find a proper model for it, monthly precipitation data of synoptic meteorological station (mm) in a 60-year period (1951-2010) are derived from Mete- 


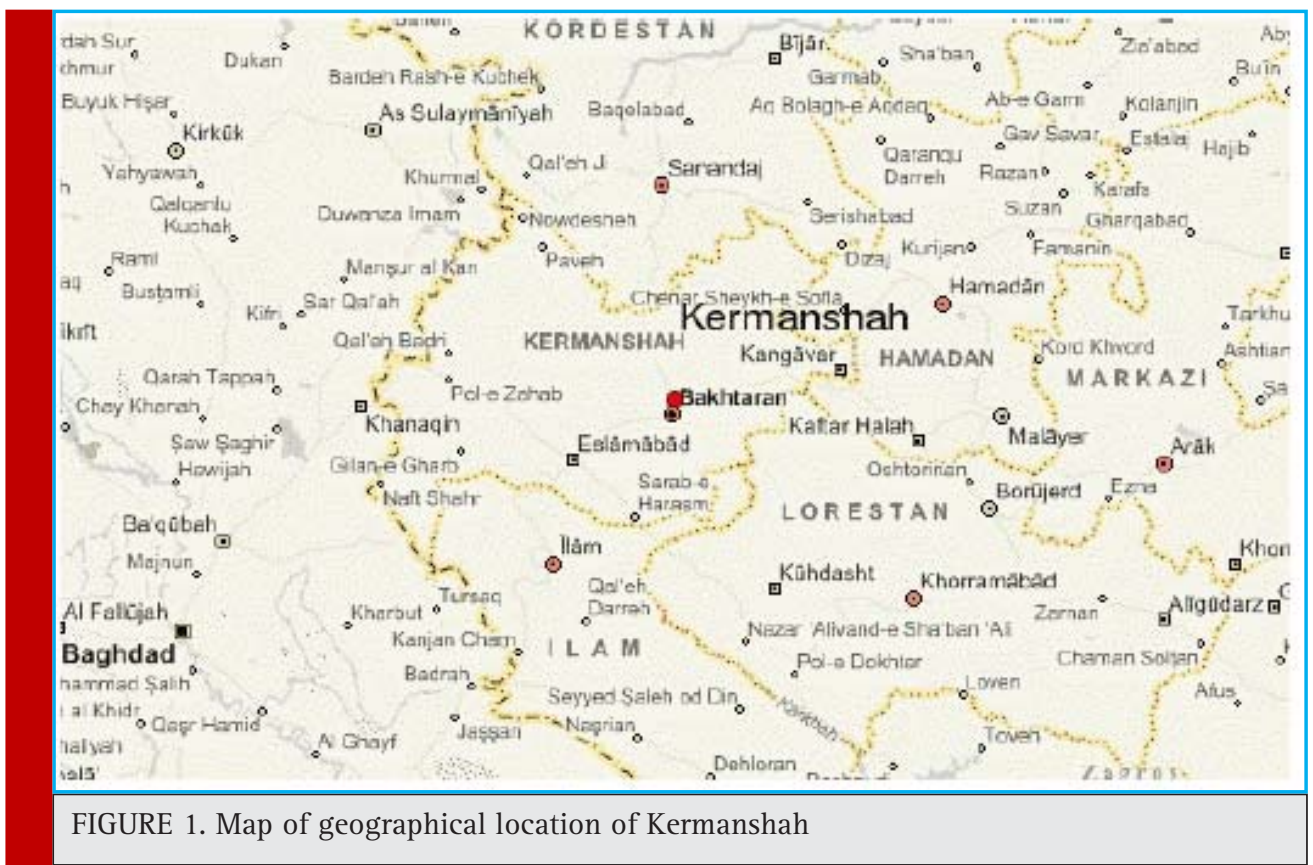

orological Organization of Iran. Seasonal precipitation is a collection of monthly rainfall and annual precipitation is a collection of seasonal rainfall. The obtained data are restored using correlation method and regression model. Data homogeneity is evaluated using Run test so as to be sure homogeneity of data in a 60-year period. In the first place, this test is employed to indicate that time series are non-parametric. In doing so, statistical series are arranged in ascending order. In this test, having no defined trend indicates that data are random. If we find a trend, data are not random. To show that data are random, the following test was carried out as per Mitchell et al (1996):

$$
T=\left[\frac{4 p}{n(n-1)}\right]-1
$$

Where $\mathrm{T}$ is Kendall's statistic, $\mathrm{n}$ is total statistical years, and $\mathrm{P}$ is total number of ratings bigger than $n_{i}$ placed under it and can be determined through the following relation:

$$
P=\sum_{i=1}^{n} n_{i}
$$

The following equation tests the significance of $\mathrm{T}$ :

$$
(T)_{t}= \pm t_{g} \sqrt{\frac{4 n+10}{9 n(n-1)}}
$$

Where $t_{\sigma}$ is critical value of normal standard (z) with the test probability level which is 1.96 at the confidence level of $95 \%$. If $-T,<T<+T$, series are random with no trend. $T<-T_{t}$ indicates a downtrend and if $T<+T_{t}$ a ris- ing trend is governs the time series (16). If $\mathrm{n}$ represents a 60 -year period, the obtained values would be \pm 0.089 .

To determine the trend direction, type, and time, graphic Kendall test has to be carried out. In calculating thestatistics using graphical sequential mann-kendalltest for detection of change time, in two phases of beginning to end, and vice versa, plotted in one graph, change point appears well. Detailed (short term) procedures, change in position, or starting point of the series are examined using time series graphs of $u(t)$ and $u^{\prime}(t)$. If you graph $u$ and $u^{\prime}$ sequences indexed by $i$, when the trend is significant, the two lines intersect, outside the range of \pm 1.96 , at the starting point and move in opposite direction. This intersection point is referred to as a leap. While, if there was no trend, the two sequences ( $u$ and $u^{\prime}$ ) would move on roughly in a parallel direction or intersect each other in a several points in a way that result in no change in direction. $U$ graph is plotted based on year and $u^{\prime}$ is defined to show its significance of leap point. Where $-1.96<\mathrm{u}<1.96$, series are random and no certain trend can be defined. But, $\mathrm{u}>1.96$ and $\mathrm{u}<-1.96$ indicate existence of a positive and a negative trend, respectively. This study considers a two-dimensional data matrix $(12 \times 60$ : $60=$ studies years, $12=$ number of months).

If data series indicate a certain trend, the actual slope (change rate per unit of time), can be obtained using a simple non-parametric methodof Sen's slope estimator. First, obtain slope of each pair of consecutive data series using the following equation:

$$
Q_{i}=\frac{\left(x_{j}-x_{k}\right)}{j-k} \text { for } \mathrm{i}=1,2, \ldots, \mathrm{n}
$$


Where, $\mathrm{X}_{\mathrm{f}}$ and $\mathrm{X}_{\mathrm{k}}$ are data values in time $\mathrm{j}$ and $\mathrm{k}$, respectively, which differ one unit of time, $Q_{i}$ is the median value, and $\mathrm{n}$ is slope of line estimated by Sen's slope estimator. Sen's slope estimatoris obtained through the following equation:

$$
Q_{\text {med }}=Q_{(n+2) / 2}
$$

Where $\mathrm{n}$ is an even number, Sen's slope estimatoris achieved as:

$$
Q_{m e d}=\left(Q_{n / 2}+Q_{(n+2) / 2}\right) / 2
$$

If you measure $Q_{\text {med }}$ with mutual test at the confidence level of $100(1-\alpha) \%$, it is possible to obtain the actual value of the line slope. Considering zero between two derived slopes, no trend can be attributed to the time series with this confidence level. Otherwise, significant trend of time series, at the considered level of confidence, is proved. Total monthly precipitation data in 1996, from January to May, is not available so average precipitation value of other months are used. Months of the year are divided into two groups, warm and cold months, and trends in each group are examined and compared separately.

\section{RESULTS AND DISCUSSION}

Average precipitation over Kermanshah per month $( \pm$ Standard Deviation) is $36.18 \mathrm{~mm}( \pm 42.52)$ and the highest amount of precipitation per month during the statistical period (60 years) is $494.8 \mathrm{~mm}$ recorded in 1974 . The least amount of precipitation is zero and recorded during summer. Mann- Kendall test results for total annual precipitation are calculated and drawn. During the studied period, no trend is detected in average precipitation over Kermanshah weather station within the significant levels of the test since $u$ and $\mathrm{u}^{\prime}$, at no time interval, intersect outside the meaningful range \pm 1.96 (Chart 1). From 1968 to 1975 the graph falls above 1.96; changes which indicate leapsin total annual precipitation during these years.

Distribution of annual precipitation during the studied years is drawn. The least amount of annual precipitation is 215.8 recorded in 1995 and the highest amounts of precipitation is 785.5 recorded in 1996 and 783.9 recorded in 1957 (Chart 2).

According to the results of Mann-Kendall diagram, no significant trend is detected in annual precipitation data recorded during the studied period (60 years).Sen's slope estimator confirms the obtained results. The value of statistic in $\mathrm{Z}$ is 0.03 . With respect to obtained values for the highest (1.67) and lowest (-2.26) amount of $Q$, with confidence level of 95\%, it may be concluded that null hypothesis of this test is confirmed and no trend in detected in the precipitation data recorded during the 60-year period. In Sen's slope estimator test, null hypothesis is: there is no trend is the studied period. Considering the obtained $\mathrm{P}$-value ( $>0.05$ ) and available

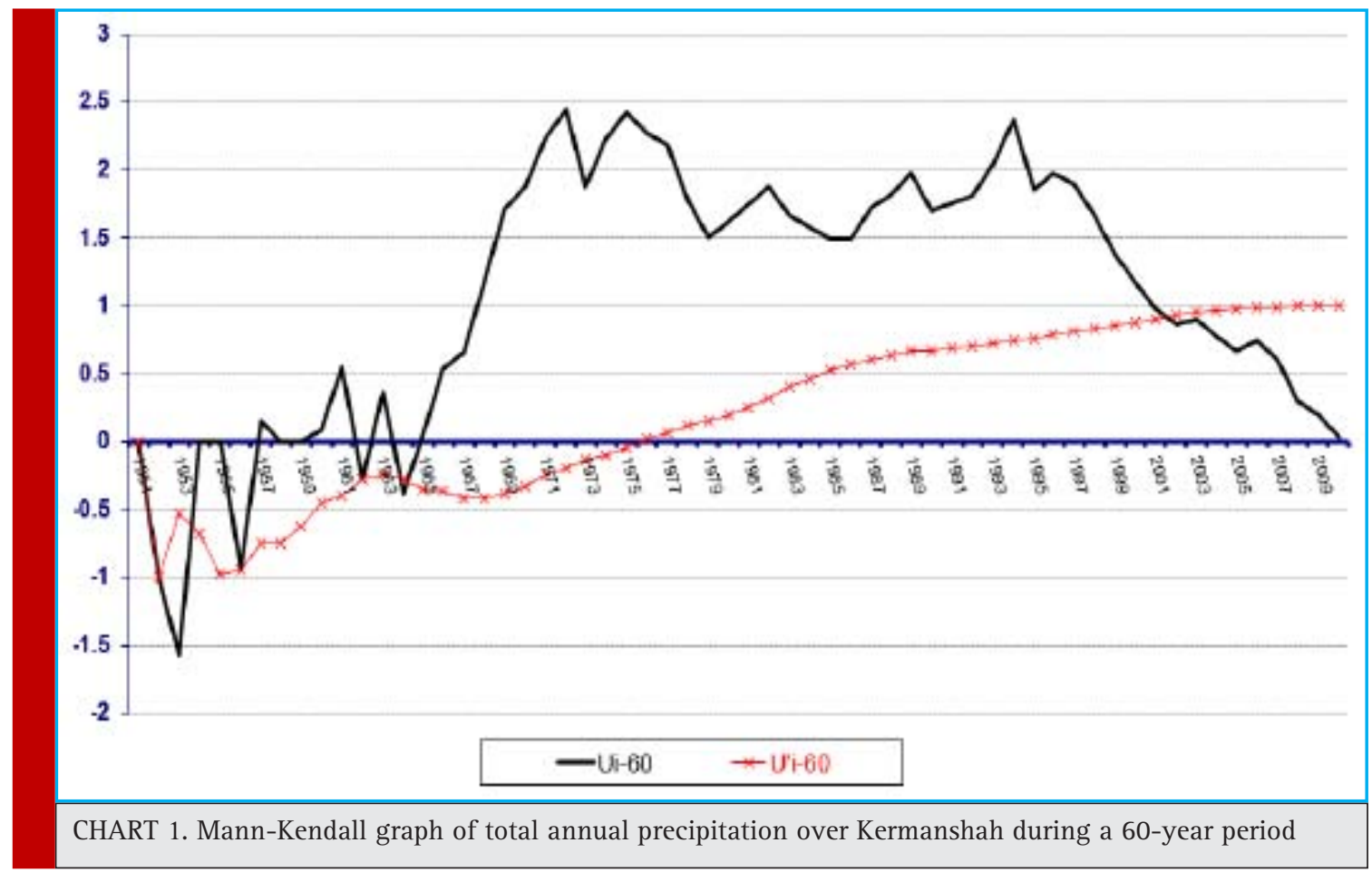




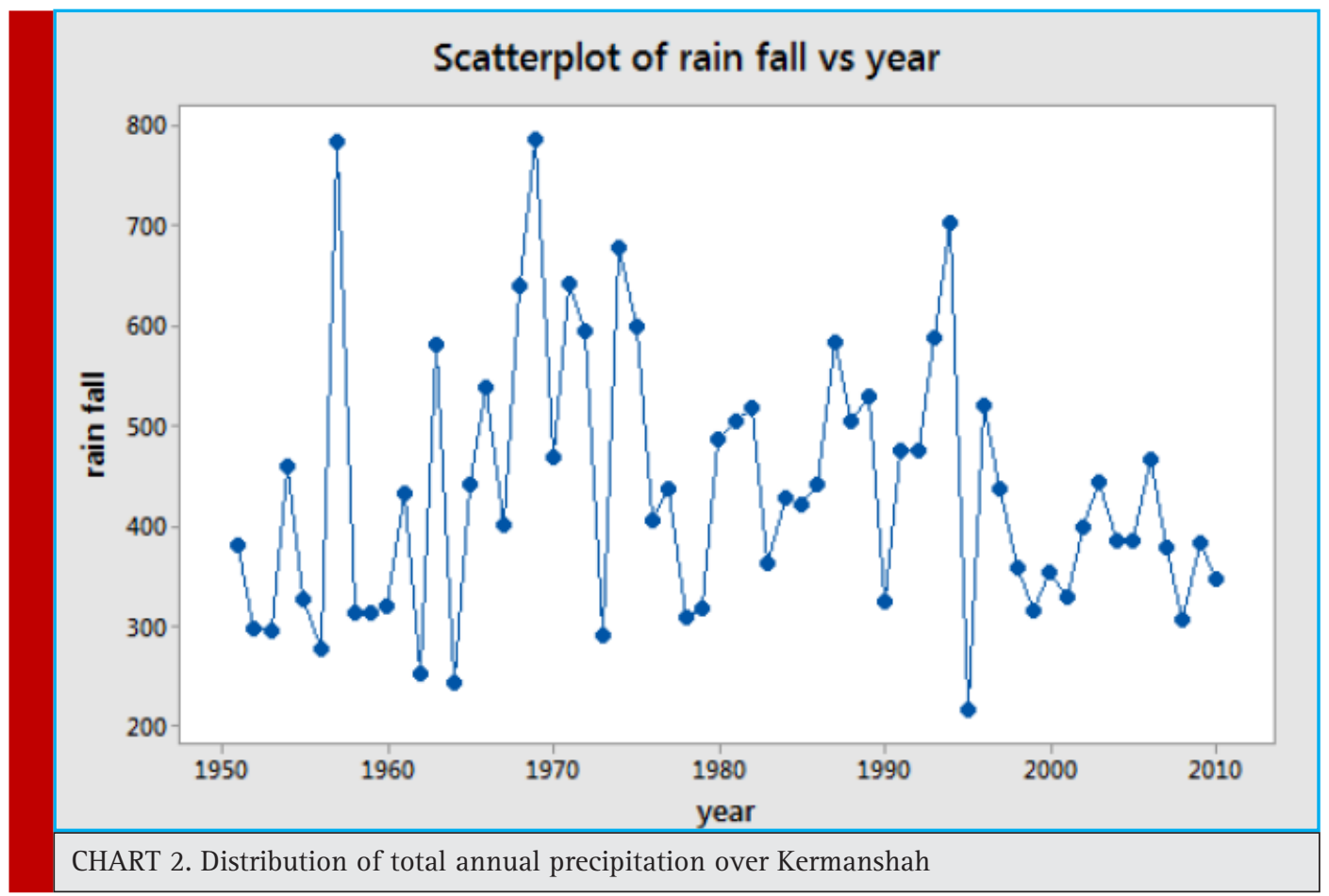

data, the assumption of existence of a trend in the studied period is rejected. In other words, no trend can be attributed to existing data. With regard to the highest and lowest slope values, zero depends on the interval between these two values. Therefore, null hypothesis of the test is confirmed based on this confidence interval (Table 1).

Average precipitation over Kermanshah per month ( \pm standard deviation) is $47.9 \mathrm{Mm}( \pm 33.64)$ and the highest amount of precipitation per month during the statistical period (60 years) is $297.6 \mathrm{~mm}$ recorded in spring of 1963. Average monthly precipitation over Kermanshah during cold seasons is $169.68 \mathrm{~mm}( \pm 54.56)$ and the highest amount of monthly precipitation during cold seasons is $494.8 \mathrm{~mm}$ recorded in winter of 1947. The least amount of precipitation is zero and recorded mostly in summers.

Mann - Kendall test results of average monthly precipitation are analyzed and drawn for both warm and cold seasons. During warm seasons of the study period, the average amount of precipitation over Kermanshah weather station indicates no statistically significant trend in the significant range; however, from 1951 to 1968 , a rising trend is detected with sharp leaps and falls and positive phase of change is witnessed in precipita- tion. In 1969, a leap from average is occurredand data are considerably increased. Again, in 1977 the precipitation goes back to normal phase. Since 1978 precipitation level follows a decreasing trend which again has its own ups and downs and does not go beyond the significant level (Chart 3).

Diagram of distribution of average monthly precipitation over Kermanshah during warm seasons of a 60-year period is drawn. The lowest and highest averages of monthly precipitation during warm seasons are 0 and 148.8, respectively, recorded in 1963 (Chart 4).

According to the results of Mann-Kendall diagram for warm seasons, no significant trend is detected in monthly precipitation data recorded during the studied period (60 years).Sen's slope estimator confirms the obtained results. The value of statistic in $\mathrm{Z}$ is 0.69 . With respect to obtained values for the highest (1.11) and lowest (-63.1) amount of Q, with confidence level of 95\%, it may be concluded that null hypothesis of this test is confirmed and no trend in detected in the precipitation data recorded during the 60-year period (Table 2).

Considering the obtained P-value (>0.05) and available data, the assumption of existence of a trend in the studied period is accepted. In other words, no trend can

\begin{tabular}{|l|l|l|l|l|l|l|}
\hline \multicolumn{6}{|c|}{ Table 1. Results of Sen's slope estimator test for total annual precipitation over Kermanshah } \\
\hline variable & Time interval & Number of years & Z statistic & p-value & Qmax & Qmin \\
\hline $\begin{array}{l}\text { Amount of } \\
\text { precipitation }\end{array}$ & $1951-2010$ & 60 & 0.03 & 0.488 & 1.67 & -2.26 \\
\hline
\end{tabular}



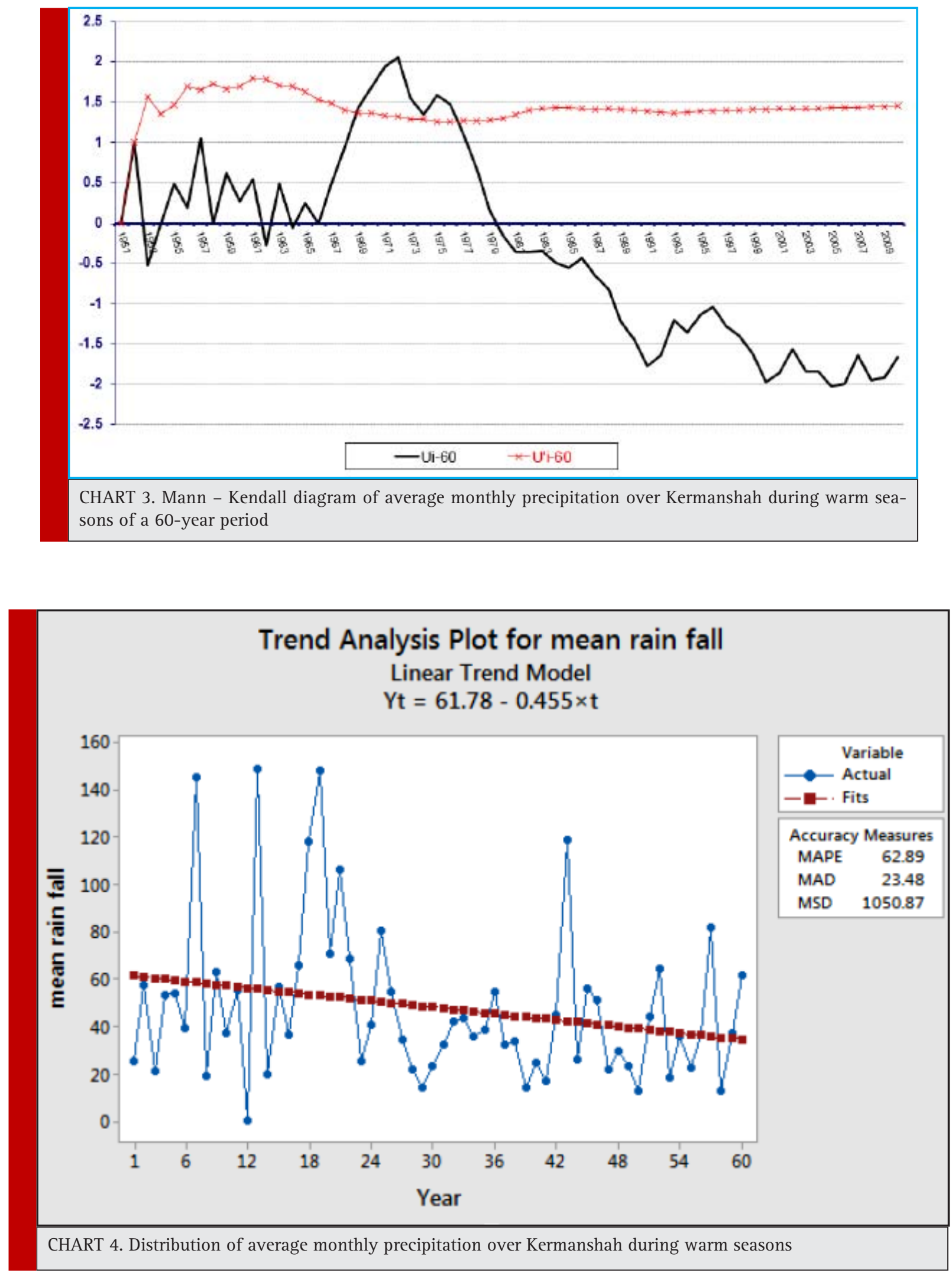
Table 2. Results of Sen's slope estimator test for total monthly precipitation over Kermanshah

\begin{tabular}{|l|l|l|l|l|l|l|}
\hline variable & Time interval & Number of years & Z statistic & p-value & Qmax & Qmin \\
\hline $\begin{array}{l}\text { Amount of } \\
\text { precipitation }\end{array}$ & $1951-2010$ & 60 & 1.56 & 0.059 & 0.06 & -0.712 \\
\hline
\end{tabular}

be attributed to existing data. With regard to the highest and lowest slope values, zero depends on the interval between these two values. Therefore, null hypothesis of the test is confirmed based on this confidence interval (table 2). Although, with regard to Sen and Mann-Kendall statistical indicators, no significant trend is detected in average monthly precipitation during warm seasons, the general trend of time series is decrescent (Chart 4). The linear equation of times series obtained by trend analysis test is $y_{t}=61.78-0.455 \times \mathrm{t}$ ( $\mathrm{t}$ is the time difference since the beginning of time series). The linear equation obtained by Sen's slope estimator is below:

$$
f(\text { year })=-0.297 \times(\text { year }- \text { first Data Year })+50.2 \text {. }
$$

Forecasts of the two employed tests for the average precipitation in warm seasons are very close and similar.

To examine existence of trend in precipitation during cold seasons, Mann-Kendall test and Sen's slope estimator are used, the results of which are as follows. During cold seasons of the studied period, no trend is detected in average precipitation over Kermanshah weather station within the significant levels of the test. In 1967, a leap from average is occurred and this sudden change continues in an upward positive direction until 1995.
Then, until the end of the study period, precipitation follows a downward trend (Chart 5).

The lowest and highest averages of monthly precipitation during cold seasons are 51.6 and 325.35, respectively (Chart 6).

According to the results of Mann-Kendall diagram, no significant trend is detected in annual precipitation data recorded during the studied period (60 years).Sen's slope estimator confirms the obtained results. The value of statistic in $\mathrm{Z}$ is 0.69 . With respect to obtained values for the highest (1.11) and lowest (-0.63) amount of $Q$, with confidence level of 95\%, it may be concluded that null hypothesis of this test is confirmed and no trend in detected in the precipitation data recorded during the 60-year period (table 3 ).

Considering the obtained P-value (>0.05) and available data, the assumption of existence of a trend in the studied period is accepted. In other words, no trend can be attributed to existing data. With regard to the highest and lowest slope values, zero depends on the interval between these two values. Therefore, null hypothesis of the test is confirmed based on this confidence interval (Table 3).

Generally, a comparison between average precipitations during warm and cold seasons indicate that

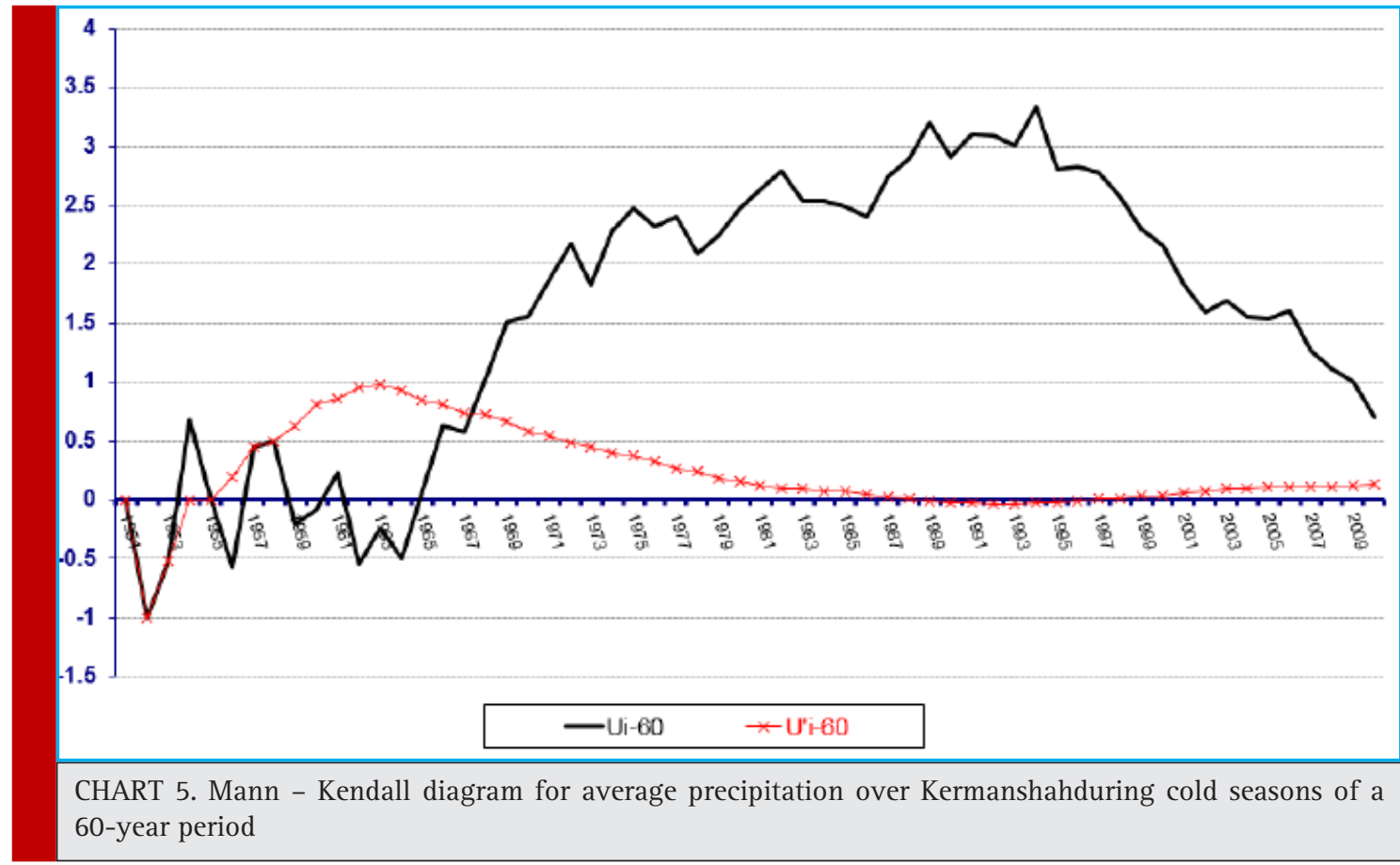




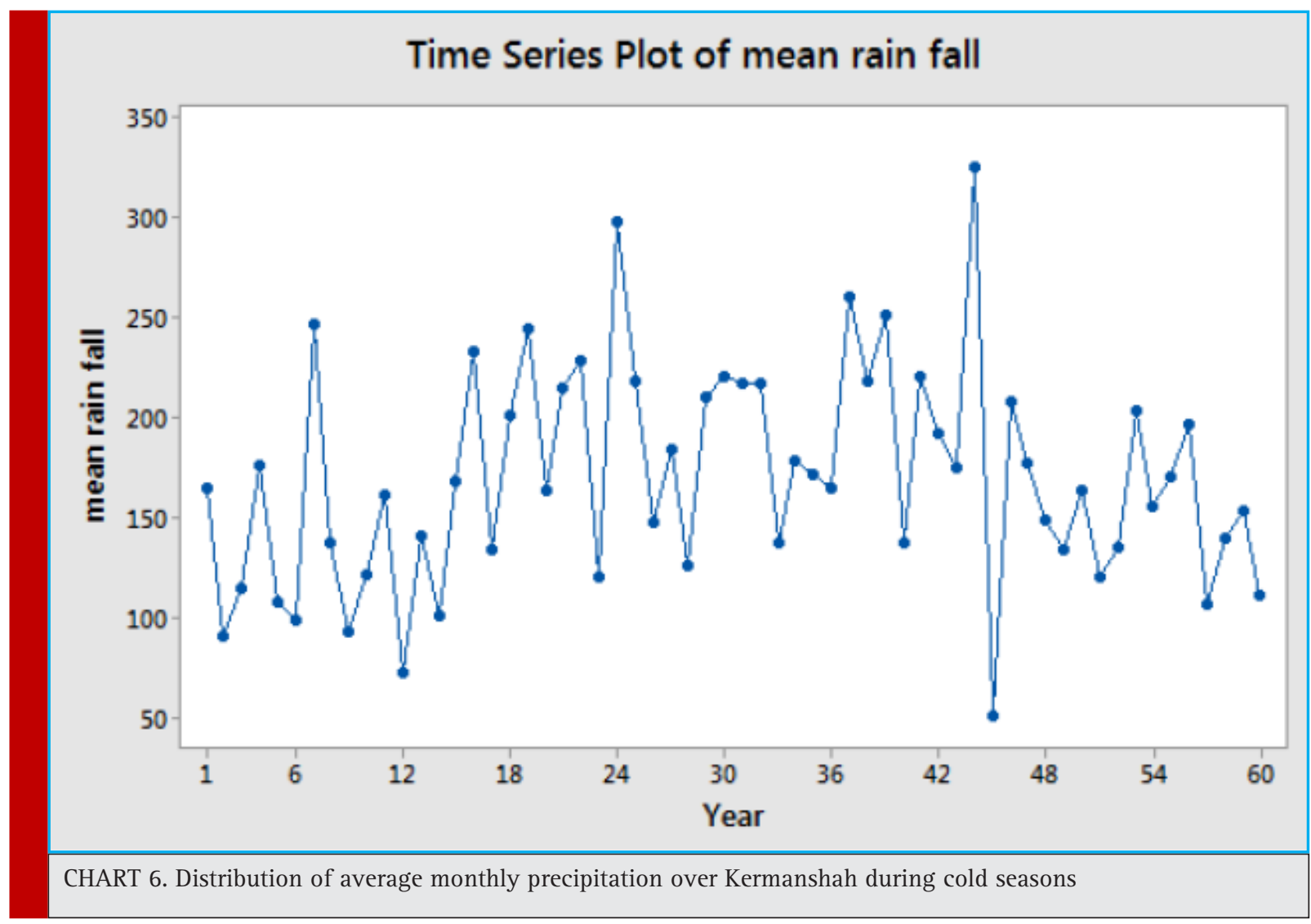

changes in warm season starts a downward trend since 1970. But an upward trend of precipitation in cold seasons changes to a downward direction since 1993. In the beginning years of the study period, changes in average monthly precipitation during warm seasons is more than cold seasons; however, the more we approach the end of the study period, the less evident are these ups and downs.

1. Statistical studies of precipitation have been largely considered since 1980. Statistical studies of Kane and Trivedi (1988), Karl (1988)and Katsoulis and Kambetzldis (1989) are among these. When compared with Iran with annual precipitation of about $260 \mathrm{~mm}$, Kermanshah, with average annual precipitation of $434 \mathrm{~mm}$, is regarded as an area with high rate of precipitation. Trend step changes in precipitation are evident in different stations.
But in most stations, the trend of change seems not be statistically significant. Average monthly precipitation over Kermanshah during warm and cold seasons indicates no significant trend of change. The results of this study are different from the findings of the study carried out by Jahanbakhsh et al. in which they measured changes in precipitation and temperature of Karkha region. This difference may be due to differences in geographical location of the two regions (19). But, Hejam et al. research is consistent with the current study. They examined trend of changes in seasonal and annual precipitations over several meteorological stations and because of lack of trended and un-trended series they could not attribute a certain trend to seasonal and annual precipitations of the studied region, ( Jahanbakhsh et al., (2010) Negaresh et al (2012) .

Table 3. Results of Sen's slope estimator test for average precipitation over Kermanshah during
cold seasons
\begin{tabular}{|l|l|l|l|l|l|l|} 
variable & Time interval & Number of years & Z statistic & p-value & Q min & Q max \\
\hline $\begin{array}{l}\text { Average } \\
\text { precipitation }\end{array}$ & $1951-2010$ & 60 & 0.69 & 0.246 & -0.63 & 1.11 \\
\hline
\end{tabular}


Investigation seasonal (warm and cold) trend of precipitation indicated that average precipitation during warm seasons of the 60-year period is generally downward; however, this trend is not significant at 0.05 . The results of this study are consistent with the results obtained from the study of Alijani et al. (2012). During summer, cloud formation and precipitation is not possible over a wide range of Iran. Therefore, this season is the driest season. In the 60-year period, because of lack of precipitation during summer, changes in average precipitation during warm seasons was similar to springs which was different to that of Katirai et al report. They found a decreasing trend for spring precipitation in Iran. Although, they examined precipitation trend of the whole country of Iran from 1960 to 2001 but we only studied Kermanshah with more detail and during a longer period. Negaresh et al. (2012 ), in a statistical investigation of changes in precipitation over Saqqez, found similar results and decreasing trend for precipitation during summer. Although we found no significant trend for precipitation during warm seasons, direction of changes in precipitation trend was downward.

The current study found no trend for precipitation during cold seasons and in this regard our findings are consistent with Alijani et al 2012 . studies of precipitation during cold seasons indicated no trend, either, and these findings are consistent with the study of Negaresh et al. (2012). In case of finding a trend, precipitation forecast for coming years would be possible.

\section{CONCLUSION}

In general, annual precipitation over Kermanshah, during a 60-year period, from 1951 to 2010, follows no specific (downward or upward) trend. General changes in trend of precipitation during warm seasons, although non-significant, follow downward directions. Also, some leaps of change are witnessed in annual and seasonal trend of precipitation.

\section{ACKNOWLEDGMENT}

The researchers wish to thank Deputy of research and technology of university for their financial support of this project (No.93502), and Weather Organization for their cooperation and allowing us to use data recorded in synoptic meteorology station.

\section{REFERENCES}

Abdul Aziz 0.I., and Burn D.H. (2006) Trends and variability in the hydrological regime of the Mackenzie River Basin, Journal of Hydrology 319:282-294.
Ahmadi A., Marufi S., ZareAbyaneh H. andHeidari M. (2010) Statistical analysis of rainfall trend in Kermanshah province by $\mathrm{f}$ Mann-Kendall test. First Conference of Iranian Water Resources Research. Kermanshah University of Technology.29-37.

Alijani B., Mahmoudi P. and Chogan A.J. (2012) A study of annual and seasonal precipitation trends in Iran using a nonparametric method (Sen's slope estimator). Journal of climate resaerch 3 (9); 105 - 106.

Angel J.R.and Huff F.A. (1997) Changes in heavy rainfall in Midwestern United States. Journal of water Resources planning and management 123(4): 246-249.

Chen H., Guo S., Xu C.Y. and Singh V.P. (2007) Historical temporal trends of hydro-climatic variables and runoff response to climate variability and their relevance in water resource management in the Hanjiang basin. Journal of Hydrology 344:171184.

Gellens D. (2000) Trend and Correlation Analysis of k-Day Extreme Precipitation over Belgium. Theoretical and Applied Climatology 66:117-129.

Hejam S., Khoushkhou Y. and ShamsaldinVandi R. (2008) Annual And Seasonal Precipitation Trend Analysis of Some Selective Meteorological Stations In Central Region of Iran Using Non-Parametric Methods. Physical Geography Research Quarterly 40(64): 157-168.

Jahanbakhsh S., RahimiBondarabadi S., Hosseini A., Rezaei S. andKhosh Zaman T. (2010) Annual rainfall and temperature trends in Karkharivar basin. 4th international congress of the Islamic world geographers.

Javeri M.(2003) Temperature and precipitation changes in Iran. $\mathrm{PhD}$ thesis of geography. University of Tehran 2003.

KamaliGh. (1996) Severe changes in rainfall in different parts of the country in the last ten years. The first regional conference of climate changes. Tehran, 21-23 May 1996.

Katirai, P.S., Hejam S. and Irannejad P. (2007) Daly precipitation frequency and intensity changes in precipitation trend distribution over 1960-2001.Journal of the Earth and Space Physics 33(1): 67-83.

Keily G., Albertson J.D. and Parlange M.B. (1998) Recent Trends in Diurnal Variation of Precipitation at Valentia on the West Coast of Irland. Journal of Hydrology207: 270-279.

Matyasovszky I., Bogardi I., Bardossy A. andDuckstein L. (1993). Estimation of Local Precipitation Statistics Reflecting Climate Change, Water Resources Research. 29, 3955-3968.

Mitchell. J.M., ChairmanJ., Dzerdzeevskii B., Flohn H., Hofmeyr W.L., Lamb H.H., Rao K.N. and Wallen C.C.(1966)Climatic Change. Technical Note No. 79. (Report of a working group of the Commission for Climatology). WMO 195.

Negaresh H., Sari B. and Darayi M. (2012) The Statistical Survey of Precipitation Changes in Saqqez. 16(42);239-59.

Piccarreta M.,Capolongo D. and Boenzi F.(2004) Trend Analysis of Precipitation and Drought in Basilicata from 1923 to 2000 within Southern Italy Context. International journal of climatology 24, 907-922. 
Serrano A., Mateos V.L. and Garcia J.A. (1999) Trend analysis of monthly precipitation over the iberian peninsula for the period 1921-1995. Physics and Chemistry of the Earth, Part B: Hydrology, Oceans and Atmosphere 24(1-2):85-90.http:// www.iranicaonline.org/articles/kermanshah-01-geography

Turgay P. and Ercan K. (2005)Trend Analysis in Turkish Precipitation data. Hydrological Processes 20(9): 2011-2026.
Vivekanandan N. (2007) Analysis of Trend in Rainfall Using Non Parametric Statistical Methods.International symposium on rainfall rate and radio wave propagation, American institute of physics: 101-113.

Xu Z.X., Takeuchi K. and Ishidiaira H. (2003) Monitoring trend step changes in precipitation in Japanese precipitation. Journal of Hydrology 279: 144-150. 